\title{
Gonial Angle Changes Based on Age Group on Mongoloid Race in Medan City in Terms of Lateral Cephalometric Radiograph
}

\author{
Maria Sitanggang, Trelia Boel, \\ Department of Oral and Maxillofacial Radiology \\ Faculty of Dentistry, Universitas Sumatera Utara \\ Medan, Indonesia
}

\author{
Sondang Pintauli \\ Department of Dental Public Health Faculty of \\ Dentistry, Universitas Sumatera Utara \\ Medan, Indonesia
}

\begin{abstract}
The gonial angle (mandibular angle) is a radiomorphometric index from the angle of the mandible, which is formed between the inferior border and the posterior border of the mandible. The mandible is one of the causes of various forms of malocclusion. This study was conducted to determine the changes and differences of gonial angle of each age group in Mongoloid race in Medan City in terms of lateral cephalometric radiograph. The type of this research is analytical using cross-sectional design at Oral and Maxillofacial Radiology Installation of Dental Faculty of Dentistry, University of Sumatera Utara (USU), with sample of 150 people divided into five age groups. This research describes that the result of the largest sequential goni sequence were found in the age group 4-12 years $\left(127,43^{\circ}\right)$, age $>60$ years $\left(126.61^{\circ}\right)$, age 3560 years $\left(124.82^{\circ}\right)$, age $25-34$ years $\left(122.10^{\circ}\right)$, and the age of $13-24$ years $\left(119.96^{\circ}\right)$. The conclusion of this study is that there is a significant difference from the gonial (mandibular angle) of each age group, on Mongoloid race in Medan City in terms of lateral cephalometric radiographs where the change of gonial angle is estimated by the effect of the teeth and age conditon.
\end{abstract}

Keywords-gonial angle, cephalometri

\section{INTRODUCTION}

The gonial angle/gonion (gonial angle) is a radiomorphometric index, the jaw angle formed between the inferior mandibular border and the posterior border of the mandible. The term "Gonion" is derived from the word "ywvtx" in Greek meaning 'angle' [1]. Mandible has an important role in determining one's facial features. The morphological changes in the mandible are affected by the teeth and age condition during the life process. Given the importance of facial aesthetic maintenance, evaluation of the effects of age and sex on the mandibular gonial angle is very useful [2].

The most common skeletal anomalies are asymmetrical and maxillary and lower positions, temporomandibular joints and associated head and facial structures. The mandible is one of the causes of malocclusion. The mandible develops through the remodeling process (aposition and resorption) [3]. In orthodontics, oromaxilofacial surgery, cephalometric radiography is an important source of information [4,5].
Lateral cephalometry is a good choice for the evaluation of mandibular morphology $[4,6]$.

Huumonen, et al. (2010), conducted a large study of gonial angle, high ramus and condyles against edentulous patients. Huumonen, et al., (2010) concluded that morphological changes of the mandible as a consequence of tooth loss can be expressed as the widening of gonial angle and shortening of ramus and ramus height [2].

Facial aging is a dynamic process involving soft tissue aging and bone structure. Shaw, et al. (2010), conducted a study of mandibular changes to 120 subjects (consisting of three age categories: 20-40 years, 41-64 years, and $>$ or $=65$ years). The study used three-dimensional radiography, with edentulous patients excluded. From this measurements, the height of the ramus, the mandibular height, and the length of the mandibular body decreased significantly. The mandible angle increased significantly for both sexes with the increased age. This research describes specific aspects of bone on mandibular changes with age in both sexes, and what impact structural changes may have on the overall facial aesthetics [7].

The influence of individual age and gender on the size of the gonial angle is controversial, although several studies have shown widening of the gonial angle with increasing age. Many articles had reported different results. Chole et al., 2013, conducted research on dentulous and edentulous subjects. A total of 1,060 panoramic radiographs were evaluated: dentulous groups, 854 subjects and edentulous groups, 206 subject patients. Subjects were grouped into six 10-year age groups. The gonial angle, antegonial angle, and antegonial depth are measured by panoramic radiography. The results of the study were age correlation and gonial angle, antegonial angle and antegonial depth was not significant. Significant differences in the angle of the mandible are found between men and women. Differences in gonial angles may be involved as a forensic tool for gender determination but not suitable for age determination [6]. Shilpa, et al. (2014) conducted a study on the combined effects of age and sex in measuring the gonial angle in the North Indian population group of Haryana. Shilpa, 
et al., (2014), concludes that age has a significant influence on the gonial angle [8].

Research conducted by Bhardwaj, et al., (2014) to evaluate the relation of the gonial angle of the mandible to gender and age influence using radiographs concluded that there was no significant difference in all age groups [9].

\section{MATERIALS AND METHODS}

This research was an analytical research using crosssectional design, conducted in Oral-Maxillo Facial Radiology Installation, Faculty of Dentistry, Universitas Sumatera Utara (USU). The research population is the people of Medan City whom are Mongoloid race. The sample of the esearch is the people of Medan City whom are three previous generations of the origin of Mongoloid race.

A sample of 30 people for each age group was used in this research. Sample selection method was done by purposive sampling method that fulfilled inclusion and exclusion criteria. Inclusion criteria:

1. Group 1 (Age 4-12 years):

a. In the period of primary teeth: complete primary teeth, have not experienced with mixed tooth periods. There has never been orthodontic treatment. b. In mixed tooth period: there is no premature loss of deciduous teeth, there is no missing teeth of permanent teeth, not using artificial teeth. There has never been orthodontic treatment.

2. Group 2 (Age 13-24 years):

a. In mixed tooth period: there is no premature loss of deciduous teeth, there is no missing teeth of permanent teeth, not using artificial teeth. There has never been orthodontic treatment.

b. In the permanent tooth period: complete teeth (with 28 teeth, not using artificial teeth), except for third molars. Never done orthodontic treatment.

3. Group 3 (Age 25-34 years); and Group 4 (35-60 years)

In the permanent tooth period: complete teeth (with 28 teeth, not using artificial teeth), except for third molars. There has never been orthodontic treatment.

4. Group of 5 (age> 60 years): full edentulous, full denture wear. There has never been orthodontic treatment.

Exclusion criteria:

1. Have or are suffering from systemic disease.

2. History of jaw surgery, odontectomy, micrognathia, pathological conditions in the mandible, the presence of deciduous /persistent teeth.

3. There is deep caries with crown loss, fullcrown, or space maintainer/space regainer.

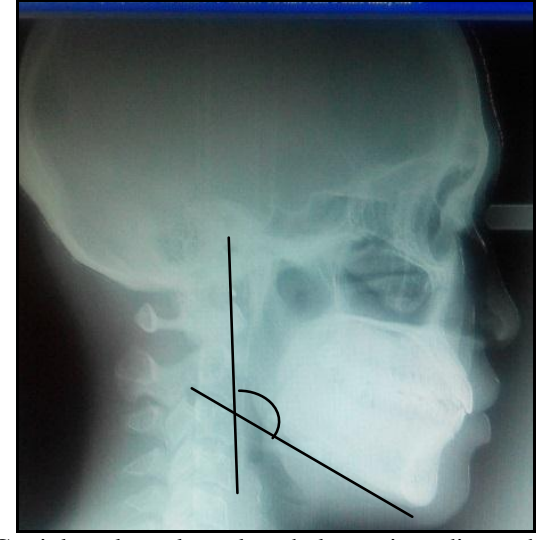

Figure 1. Gonial angle on lateral cephalometric radiography.

After completing the questionnaire, a digital of the lateral cephalometry was performed on the sample using Orthopantomograph Instrumentarium, model QC 200 D 1-4-1, 2012. Measurements were done on the computer.

Data analysis was done by One Way Anova test when the calculated data was normal distribution, on the contrary used Kruskal Wallis test when the data was not normally distributed. Ethical clearance was obtained from the Research Ethics Committees of Faculty of Medicine, Universitas Sumatera Utara.

\section{RESULTS}

TABLE I. TESTS OF NORMALITY

\begin{tabular}{|c|c|c|c|c|c|c|c|}
\hline & \multirow{2}{*}{ Age } & \multicolumn{3}{|c|}{ Kolmogorov-Smirnova } & \multicolumn{3}{|c|}{ Sharipo-Wilk } \\
\hline & & Statistic & $D f$ & Sig. & Statistic & $D f$ & Sig. \\
\hline \multirow{5}{*}{$\begin{array}{l}\text { Gonia } \\
1 \\
\text { angle }\end{array}$} & Group 1 & .161 & 30 & .047 & .936 & 30 & .071 \\
\hline & Group 2 & .143 & 30 & .121. & .967 & 30 & .472 \\
\hline & Group 3 & .115 & 30 & $.200^{*}$ & .974 & 30 & .667 \\
\hline & Group 4 & .206 & 30 & .002 & .920 & 30 & .027 \\
\hline & Group 5 & .106 & 30 & $.200^{*}$ & .971 & 30 & .579 \\
\hline
\end{tabular}

TABLE II. VALUE OF THE GONIAL INFLUENCE IN FIVE AGE

\begin{tabular}{|c|c|c|c|c|c|c|c|c|}
\hline \\
\hline $\begin{array}{l}\mathbf{G} \\
\mathbf{R}\end{array}$ & \multirow{2}{*}{$\mathbf{N}$} & \multirow{2}{*}{ Mean } & \multirow{2}{*}{$\begin{array}{c}\text { Std. } \\
\text { Deviation }\end{array}$} & \multirow{2}{*}{$\begin{array}{l}\text { Std. } \\
\text { Error }\end{array}$} & \multicolumn{2}{|c|}{$\begin{array}{l}\text { 95\% Confidence } \\
\text { Interval for Mean }\end{array}$} & \multirow{2}{*}{ Min. } & \multirow{2}{*}{ Max. } \\
\hline $\begin{array}{l}\mathbf{U} \\
\mathbf{P}\end{array}$ & & & & & $\begin{array}{l}\text { Lower } \\
\text { Bound }\end{array}$ & $\begin{array}{c}\text { Upper } \\
\text { Bound }\end{array}$ & & \\
\hline 1 & 30 & 127.4300 & 4.49790 & 82120 & 125.7505 & 129.1095 & 119.20 & 134.30 \\
\hline 2 & 30 & 119.9633 & 5.27234 & .96259 & 117.9946 & 121.9321 & 107.80 & 131.90 \\
\hline 3 & 30 & 122.1000 & 6.17944 & 1.12821 & 119.7926 & 124.4074 & 108.50 & 132.80 \\
\hline 4 & 30 & 124.8200 & 6.25572 & 1.14213 & 122.4841 & 127.1559 & 111.30 & 133.40 \\
\hline 5 & 30 & 126.6133 & 5.01162 & .91499 & 124.7420 & 128.4847 & 115.70 & 138.40 \\
\hline Total & 150 & 124.1853 & 6.09404 & .49758 & 123.2021 & 125.1686 & 107.80 & 138.40 \\
\hline
\end{tabular}




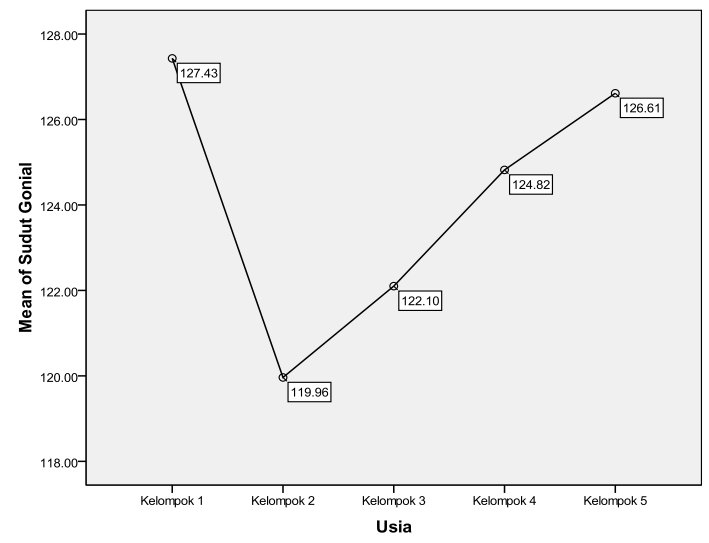

Figure 2. Graph of average value gonial angle.

The mean of gonial angle values from the five age groups (Table II.) showed a difference in each age group. The highest mean values to the smallest sequence were in group 1 (aged 4-12 years), group 5 (age> 60 years), group 4 (35-60 years), group 3 (Age 25-34 years); and the last Group 2 (Ages 13-24) (Figure 2).

\section{TABLE III. STATISTICS TEST}

\begin{tabular}{|l|c|}
\hline & Gonial Angle \\
\hline Chi-Square & 32.308 \\
\hline Df & 4 \\
\hline Asymp. Sig. & .000 \\
\hline \multicolumn{2}{|c|}{$\begin{array}{r}\text { a. Kruskal Wallis test } \\
\text { b. Grouping variable: age }\end{array}$} \\
\hline
\end{tabular}

Based on Kruskal-Wallis test results obtained $\mathrm{p}$ value $=0.000<0.05$, it is concluded there is a significant difference from the gonial angle among the five age groups (Table III.).

\section{DISCUSSION}

Mandibula consists of body and ramus. Bone growth is a complex process involving biochemical and physical stimuli, and is not yet fully understood $[10\}$. In the neonate, the mandible is made up of two parts (ie, parts united in the midline). At the end of the first year the two parts of the mandible are essentially united like parabolic bones. Various parts of the mandible include the body and two ramus that support the condyle and the coronoid process. The mandible is formed from intramembranous tissue. The primary cartilage of the mandible (Meckel cartilage) disappears early during intrauterine life with only a few remnants, namely referred to as maleus and ossicles incus in the middle of the ear and sphenomandibular ligaments. Therefore, cartilage cartilage comes from secondary cartilage. In general, the growth of head condyle occurs in an upward and backward direction [11, 12].

The principle of growth and development of the mandible, in addition to remodeling, there is also a displacement to the anterior and inferior. Endocondrial ossification in the condyle influences on the posterior mandibular growth. Aposition and remodeling will cause the mandible to grow larger. The length of the mandible increases due to the posterior apposition of the ramus and resorption in the anterior ramus. The increase in mandibular height is largely due to the growth of alveolar bone. The chin becomes more prominent because the mandible is elongated and there is little bone enhancement in the chin but does not occur again after adolescence [11,13].

The largest gonial angle is found in groups 1 (4-12 years old), and subsequently until the age of 13-24 years is decreased. In the age group of 25-34 years the size of the gonial angle will increase, then the age group of 35-60 years to the age group $>60$ years (edentulous). The results of this study are consistent with the theories of Peterson [14].

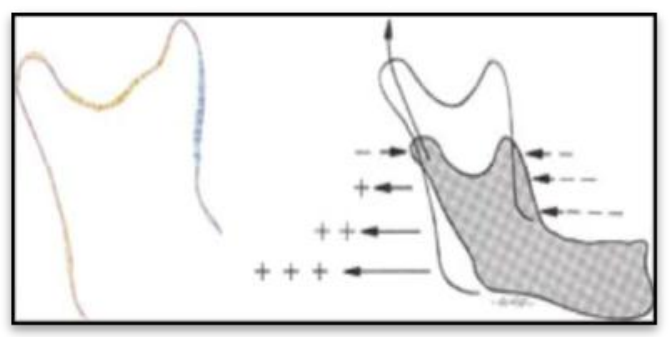

Figure 3. Growth of the mandible from birth to adulthood, causing a large decrease in gonial angle [12].

After birth, the mandibular body gradually extends in a horizontal direction especially behind the mentale foramen to produce a place for three permanent teeth. Meanwhile, the vertical direction of the height of the corpus increases with the growth of the alveolar bone which will become a place for the root of the teeth and the development of permanent teeth. The angle of the mandibular angle is even more taper, $\pm 140^{\circ}$ [14].

In adulthood, the mandibular canal is closer to the milohyoid. The ramus is increasingly vertical so that the angle on the mandibular angle is $110-120^{\circ}$. As old age decreased bone is getting bigger due to the occurrence of alveolar bone resorption. The mandibular canal and the mental foramen are closer to the alveolar bone. The angle of the mandibular angle becomes duller at $\pm 140^{\circ}$ [14].

Many studies has been done to evaluate mandibular morphology, such as the measurement of gonial angles as well as ramus and high condylar. Changes in mandibular morphology after birth are estimated to be influenced by teeth (mastication) and age. Age, systemic factors, and tooth loss may alter the gonial angle [1,2,4,6-9].

The morphology of mandibular basal bone is generally altered in association with decreased masticatory muscle function as a result of aging. In addition, the decrease in the height of the ramus with age may occur due to anterior rotation-mandibles. The gonial angle and width of bigonial increases with the increased of age, however, the height of the ramus increases and then decreases as the increased of age [14].

Research on the size of larger gonial angles in edentulous individuals compared with people with teeth has been done. However, the study has different results 
[1,2,4,6-9]. The mandibular base form, especially the gonial angle, is related to the function and shape of the mastication muscles. Age, mastication of muscle changes in function and structure in edentulous patients, seen to have decreased contraction of activity and lower muscle density compared with patients with teeth. Because the masseter and medial pterygoideus muscles work in the gonial angle area, the contraction forces of these muscles also affect the mandible's basic shape. Strong activity of anterior masseter and temporalis muscles is associated with greater posterior facial heights, flat mandibular plane and small gynecological angle [2]. Most, dentate subject have less GA than the edentulous subject. In partial or total edentulism, the function of the masseter and temporal muscle decreases and this may affect the angle of the mandible [15, 16].

The morphology of superficial masseter muscles in the gonial area is more widespread in dentate subjects than in edentulous. Mastication muscles change function and structure with the age of edentulous subjects. In computed tomographic scans the activity of electromyography and muscle density is lower on the edentulous subject than the dentate subject. The occurrence of chewing muscle atrophy may be one of the factors that cause changes to the mandible [1,17]. Another possible additional factor is the loss of intermaxillary support due to tooth loss, allowing the medial pterygoid masseter and muscle to pull out the unobstructed pull on the mandible $[1,18]$.

The conclusion of this study is that there is a significant difference from the gonial angle of the mandible, of each age group, on Mongoloid race in Medan City in terms of lateral cephalometry which may be influenced by occlusal circumstances (teeth and mastication conditions) and age.

\section{ACKNOWLEDGMENT}

This research was conducted with the support by TALENTA grant fund from Universitas Sumatera Utara, 2017.

\section{REFERENCES}

[1] S. Ghosh, M. Vengal, K.M. Pai, "Remodelling of the human mandible in the gonial angle region: a panoramic, radiographic, crosssectional study,” Oral Radiol., vol. 25, pp. 2-5, 2009.
[2] S. Huumonen, K. Sipila, B. Haikola, M. Tapio, A.L. Soderholm, T. Remes-Lyly, et al, "Influence of edentulousness on gonial angle, ramus and condylar height," J. Oral Rehabil., vol. 37, pp. 34-38, 2010.

[3] D. Kostelac, S. Mestrovi, D.K. Zlataric, M. Miksic, I.F. Zore, "Variations of mandibular variables in skeletal orthodontic anomalies," Acta Stomatol. Croat., vol. 38, pp. 127-130, 2004.

[4] Y.P. Liu, R.G. Behrents, P.H. Buschang, "Mandibular growth, remodeling, and maturation during infancy and early childhood," Angle Orthodontist, vol.1(80), pp. 97-105, 2010.

[5] E. Puricelli, "Methodology panorametry: suggestion of a method for mandibular measurements on panoramic radiographs," Head \& Face Medicine, vol. 5, pp. 19, 2009.

[6] R.H. Chole, R.N. Patil, S.W. Chole, S. Gondivkar, A.R. Gadbail, M.B. Yuwanati, "Association of mandible anatomy with age, gender, and dental status: A radiographic study," ISRN Radiology, 2013.

[7] R.B. Shaw, E.B. Katzel, P.F. Koltz, D.M. Kahn, J.A. Girotto, H.N. Langstein, "Aging of the mandible and its aesthetic implications," Plast Reconstr Surg., vol. 125(1), pp. 332-342, 2010.

[8] B. Shilpa, S.K. Srivastava, R.K. Sharma, C. Sudha, Combined effect of age and sex on the gonial angle of mandible in NorthIndian Population,” Journal of Surgical Academia, vol. 4(2), pp. 14-20, 2014

[9] D. Bhardwaj, J.S. Kumar, V. Mohan, Radiographic evaluation of mandible to predict the gender and age," Journal of Clinical and Diagnostic Research, vol. 8(10), pp. ZC66-ZC69, 2014.

[10] T.D. White, M.T. Black, P.A. Folkens, Human osteology, $3^{\text {rd }}$ ed., Elsevier, 2012.

[11] M. Reynolds, M. Reynolds, S. Adeeba, T. El-Bialyc, "3-D volumetric evaluation of human mandibular growth," The Open Biomedical Engineering Journal, vol. 5, pp. 83-89, 2011.

[12] S.E. Bishara, Text book of orthodontics. WB Saunders, 2001.

[13] R. Susanti, "Indeks perubahan jaringan lunak profil fasial lateral pasca perawatan ortodontik," Disertasi. UI. Jakarta, 2012.

[14] Peterson. (2008) Gray's anatomy of the human body. Journal of the American Medical Association [serial online]. Available: www.education.yahoo.com.references.

[15] R. Al-Shamout, A. Mohammad, R. Alrbata, A. Al-Habahbah, "Age and gender differences in gonial angle, ramus height and bigonial width in dentate subjects," Pakistan Oral \& Dental Journal, vol. 32 (1), 2012.

[16] R. Oksayan, B. Asarkaya, N. Palta, E. Simsek, O. Sökücü, E. Esman, "Effects of edentulism on mandibular morphology: Evaluation of panoramic radiographs," Scientific World Journal, 2014.

[17] Q.F. Xie, A. Ainamo, "Correlation of gonial angle size with cortical thickness, height of the mandibular residual body, and duration of edentulism," J. Prosthet. Dent., vol. 91, pp. 477-482, 2004.

[18] E. Jensen, M. Palling, "The gonial angle-a survey," Am. J. Orthod., vol. 40, pp. 120-133, 1954. 